\title{
SCIDiC
}

International Journal of Dentistry and Oral Science (IJDOS)

ISSN: 2377-8075

\section{Self-Reported Latex Glove Hypersensitivity Among Dental Personnel In Aimst Dental Institute}

Research Article

Ramesh Kumaresan ${ }^{1 *}$, Bobo Tang Kwong Jing ${ }^{2}$, Calvin Lim Yin Kai ${ }^{3}$, Chan Ying Ying ${ }^{4}$, Priyadarshini Karthikeyan

${ }^{1}$ Associate Professor, Oral and Maxillofacial Surgery, Faculty of Dentistry, AIMST University, Malaysia.

${ }^{2}$ Student, Faculty of Dentistry, AIMST University, Malaysia.

${ }^{3}$ Student, Faculty of Dentistry, AIMST University, Malaysia.

${ }^{4}$ Student, Faculty of Dentistry, AIMST University, Malaysia.

${ }^{5}$ Lecturer, Oral Medicine \& Radiology, Faculty of Dentistry, AIMST University, Malaysia

\section{Abstract}

Background: Dental personnel are at risk of latex allergy because of their regular use of latex gloves. The aim of this study was to determine the prevalence of latex glove allergy among the dental personnel in Faculty of Dentistry, AIMST University, Malaysia.

Methodology: A cross sectional study was conducted among randomly selected 234 dental personnel comprising of dental specialist, dentist, dental students, dental surgery assistant, dental clinic assistants, dental laboratory technician and dental radiographer. Data related to glove usage, signs and symptoms related to glove use, any other type of allergy and precautions taken to minimize symptoms were collected by pre-tested self-administered questionnaire.

Result: A total 58 (24.8\%) dental personnel reported allergy to latex gloves. Rashes (48.4\%) and pruritis (15.3\%) are the most common latex gloves related symptoms. Gender, years of latex glove exposure, history of atopy and allergy towards certain food showed significantly associated with latex glove allergy $(\mathrm{P}<0.05)$. Most of the dental personnel used powdered-free gloves $(34.1 \%)$ as a precaution to minimise symptoms related to latex glove allergy.

Conclusion: One fourth $(24.8 \%)$ of the dental personnel have latex glove hypersensitivity which is higher than the global prevalence. Further study and further medical assessment are recommended followed by specific measures to manage the hypersensitivity symptoms.

Keywords: Latex Glove Allergy; Dental Personnel; Occupational Hazard.

\section{Introduction}

Products of latex have been utilized since the 18th century, and for medical and dental use in particularly latex gloves have become widely used since the 1960s. Largely this has resulted from the increased awareness of the need for cross-infection control measures with acknowledgment of infectious diseases such as HIV and hepatitis C [1]. The rise of usage of latex glove came in 1988 with the AIDS scare and the "Universal Precautions" recommended by the US Centres for Disease Control (CDC) to treat certain body fluids and blood as potentially infectious [2]. Latex is found in many items in the dental surgery, being the most prominent are gloves.
It is proposed that exposure to medical gloves high in latex protein has sensitized numerous healthcare workers. Body sweat in the latex gloves may make the latex proteins soluble, further allowing absorption through skin and wearer will be sensitized easily [3]. Available statistics suggest that $8-12$ per cent of health care workers and 1-6 per cent of the general population have a latex allergy [1].

UK Adverse Reaction Reporting Project [4] reported that dentist is the largest group reported with gloves hypersensitivity compared to others, making latex hypersensitivity considered as a major occupational health problem in dental personnel who are using natural rubber latex gloves on a regular basis. Jolanski [5] also reported that dentist is the major group who has been using glove

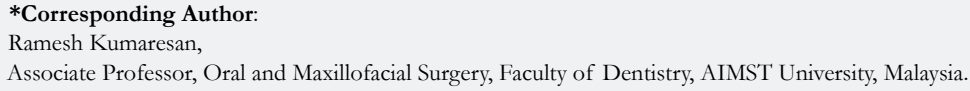

Citation: Ramesh Kumaresan, Bobo Tang Kwong Jing, Calvin Lim Yin Kai, Chan Ying Ying, Priyadarshini Karthikeyan. Self-Reported Latex Glove Hypersensitivity Among Dental Personnel In Aimst Dental Institute. Int J Dentistry Oral Sci. 2021;8(9):4437-4445. doi: http://dx.doi.org/10.19070/2377-8075-21000904

Copyright: Ramesh Kumaresan ${ }^{2021}$. This is an open-access article distributed under the terms of the Creative Commons Attribution License, which permits unrestricted use, distribution and reproduction in any medium, provided the original author and source are credited. 
for long duration, which is postulated to have increased the risk to the hypersensitivity symptoms.

Studies have documented the prevalence of latex glove allergy among various healthcare workers that ranges from $2.9 \%$ to $17 \%$. [18] In Indonesian nurse prevalence was found to be $6.1 \%$ [19] however, high prevalence $(24 \%)$ was documented for Thai nursing staff [18]. As for healthcare workers of Singapore, Siri Lanka and Jordan, the prevalence of latex allergy was within the range $(9.6 \%, 16.2 \%$ and $13.6 \%$ respectively) $[20,21]$ In all populations, the prevalence of latex sensitization and/or allergy has been associated with atopy, frequency of glove use, prior or current hand dermatitis, and the length of time of hospital work performed. Furthermore, the problem of latex allergy is made even more complex by the presence of cross reactions with a large number of fruits and vegetables examples, avocado, banana, kiwi, papaya, tomato, sweet pepper, and chestnut. Among the Malay patients who were hospitalized for allergic disease, $58 \%$ were accounted to have latex allergy.

In Malaysia, only three studies have been done to find out the prevalence of latex glove hypersensitivity.

1. M. Shahnaz et.al., (1999) found that 3.1\% of healthcare workers in Hospital Kuala Lumpur have latex hypersensitivity.

2. $26.9 \%$ latex hypersensitivity was found among dental personnel in Kelantan State (A.Yusoff et al., 2013).

3. Delay hypersensitivity symptoms (Type IV reactions) and immediate hypersensitivity symptoms (Type I reactions) reported in USIM are $8.05 \%$ and $3.4 \%$ respectively. (Fatma Ayuni Mohd Rasdi, Adi Rahmadsyah and Aspalilah Alias 2016).

This limited number of studies on prevalence of latex hypersensitivity urges on more study to be done to find out the current prevalent of latex glove hypersensitivity especially involving the dental personnel.

\section{Background}

\section{The natural rubber latex}

Natural rubber latex is an extract of sap which derived from the rubber tree (Hevea Brasiliensis) [6], one of the lactifer plants in worldwide, including Ponsettia (Euphorbia pulcherrima) and Castor Bean (Ricinuscommunis) [7]. These lactifer plants species have special cells that secrete milky substance which is the latex, circulating in the branched tubes throughout the plant tissues [7]. Latex have been used in worldwide where it is manufactured in more than 40000 industrial products in the United States which includes the dental, medical and consumer products [8]. In dentistry, a review by T. Kean and McNalley [8] has been done on the potentially latex-containing products in the dental clinic and they are listed in Table 1 below:

\section{Latex manufacturing process}

The process of manufacturing latex needs to be well understood as it explains the materials and chemicals used in the production of latex gloves. There are several processes that have to be done in producing the latex as explained by Krapp [9]. First, rubber tapping will be done by shaving off the thinnest possible layer from the intact section of rubber tree bark in order to collect the latex lump. In the beginning, the latex is a flowing liquid which will be collected as a lump because it undergone coagulation or clotting process upon exposures to the air. To prevent most of the liquid latex from coagulating before it is collected, pooled and transported, the tapper will usually add a stabilizing agent or preservatives such as ammonia or formaldehyde to prevent coagulation of the latex. The collected latex will be processed at the processing station where it is strained and concentrated. If solid latex is required by the manufacturer, the latex will be heated in which this process can destroy many but not all of the proteins. Otherwise, if liquid concentrated latex is required, there will be no heating process and most of the proteins will remains in the latex. After that the latex will be centrifuged to remove some water content and become concentrated latex with roughly $60 \%$ solid rubber and $40 \%$ protein and water. This is done under quality control where additional centrifuging is done to remove as many of the remaining impurities and proteins as possible, as well as adding some proteolytic enzymes to break down the proteins in centrifu-

Table 1. Potentially latex containing products in the dental clinic.

\begin{tabular}{|l|}
\hline \multicolumn{1}{|c|}{ Potentially latex containing products in the dental clinic [2] } \\
\hline 1. Gloves \\
2. Amalgam carrier \\
3. Intra-venous tubing and bags \\
4. Syringes (rubber stopper covered with silicone) \\
5. Bite blocks \\
6. Oxygen mask \\
7. Operative mask with rubber ties \\
8. Suction tips and suction tubing \\
9. Air or water syringe tips and irrigation tubing \\
10. Impression material \& mixing bowl \\
11. Orthodontic rubber bands and elastics \\
12. Polishing discs \\
13. Prophy cups \\
14. Bandages and tape \\
15. Stethoscopes \\
16. Blood pressure cuffs \\
17. Gutta percha \\
18. Rubber dam
\end{tabular}


gation for improvement of the latex quality. Concentrated latex is the form of latex that is used by the manufacturer to manufacture the latex gloves in the dipping process [9].

\section{Gloves manufacturing process}

Manufacturing process of gloves are the same for all manufacturers where it involves many chemicals addition, besides its process of reducing the proteins as awareness to reduce sensitivity. For latex gloves manufacturing process [10], compounding is the next process done on the concentrated latex. Chemicals like accelerators and antioxidants are added to control the vulcanization and deterioration of rubber molecules consecutively. There will be hand shape formers which will be coated with coagulant like calcium nitrate and then dipped into the latex, which will form coagulated latex glove after passage through a warm oven. Then, the glove will undergo a wet gel leaching process to remove excess additives by soaking it into the bath or water pray. Vulcanization or cross linkage of rubber is done next where the latex film is heated with the help of sulphur, accelerator and heat which finally gives strength and elasticity to the film. The workers will remove the glove from the formers where it is called stripping process. Post vulcanization or dry-film leaching will be done again to keep the gloves dry. Lubrication will be done next where hydrolysed corn starch is added as lubricant to enable easy glove wearing, and it also aims to reduce the slippery of the gloves surface when chlorination is done during the stripping process. All gloves will be checked again and then packaged to be supplied to the consumers.

\section{History of latex glove in health care workers}

The latex surgical gloves are first used in 1870s and 1880 among the healthcare worker from irritating antiseptic solutions [2]. John Hopkins Medical School surgeons started to use gloves during surgery in early 20's in order to protect their patients from bacteria of the hand. In 1952, disposable gloves are introduced [2] and hence increasing the number of gloves used. Latex glove usage increases tremendously in worldwide following the introduction of Universal Precautions by US Centre for Disease Control (CDC) due to AIDS disease in 1988, followed by Blood borne Pathogen Standard by US Occupational Safety and Health Administration (OSHA) in June 1992. [2] The mandatory use of latex glove in the 80 's has shot up the latex glove usage and latex hypersensitivity has started concurrently to be prevalent, where the first one has been reported by FDA in the early 80's [2].

\section{Latex allergen}

Latex is rich in hydrocarbon cis-1,4 polyisoprene which can crosslink to form plug which is a strong, elastic barrier that tends to be impermeable to water and returns to its original shape after multiple forces are applied to it [11]. It also contains 256 proteins [8] which contribute to $2 \%$ of weight of the natural rubber latex produced in the lactifer plant. Apparently, the polymer of polyisoprene is immunologically inert and does not causing allergic reaction [11]. Allergic reactions are associated with 11 to 13 recognized allergens from the latex proteins and also from the chemicals that are being used in dipping process of manufacturing latex gloves. The 115 to 1311 recognized allergens are water soluble membrane-bound protein causing clinical reactions. There is also evidence saying that only hev b 2, hev b 6, hev b 13 and possibly hev $\mathrm{b} 4$ are the major allergens causing latex sensitivity in adults. [12] Hev b 5 apparently exhibit close homology to other plant and fruit allergen such as Kiwi fruit protein in Pkiwi501. This amino acid homology causing the antibody has a cross reactivity between the latex and food antigens. Individuals who have food allergies like banana, avocado, chestnut, apricot, kiwi, papaya, passion fruit, pineapple, peach, nectarine, plum, cherry, melon, fig, grape, potato, tomato and celery may also have a coexisting latex allergy [13][ (Kurup et al., 1994, DH Beezhold et al., 1996). The other cause of allergic reactions are the chemicals used in the dipping process which are accelerators or antioxidants like thiuram, carbamates, and mercaptobenzothiazole which can cause cause contact dermatitis and also type iv hypersensitivity [11].

\section{Pathogenesis of hypersensitivity}

The pathogenesis of latex hypersensitivity is postulated by the American Latex Allergy Association [14] to sensitize in several ways. Inhalation of powder particle can absorb the latex allergen particle and cause sensitivity. It can also occur from absorption through the skin from latex product, where body secretions like sweat solubilized the latex allergens or it can pass through a traumatized skin, irritation or contact dermatitis. Absorption through mucous membrane from latex product can also sensitize the individual in contact with the rubber, or it can also enter directly into the body during injections or any procedures when the practitioner is using latex gloves.

\section{Types of hypersensitivity}

There are mainly three conditions in which latex sensitize the individual, which are contact dermatitis, type IV hypersensitivity and type I hypersensitivity [15]. Irritant contact dermatitis is a non-allergic, localized inflammation of the skin caused by chemical irritation that does not involve the immune system. The irritation occurs gradually with redness, itching, dryness, scaling, and cracking of the hand that allows the latex allergens entry into the body. It can also be caused by inadequate hand care, friction, perspiration or in extreme humidity and temperature conditions. Type IV hypersensitivity or also known as delayed hypersensitivity is a T-cell mediated caused by direct physical contact with substance containing latex, allowing high access of proteins, rubber accelerators and antioxidants used in manufacturing the gloves to enter the body. It is delayed onset hypersensitivity in 24 to 48 hours with sign and symptoms of erythema, scaling and vesiculation of the skin involved. In repeated exposures to the allergens, delayed hypersensitivity developed type I hypersensitivity which is an $\operatorname{IgE}$ mediated reaction toward specific protein allergen in latex. It is also associated with cross reactivity to certain food. Mast cell and basophils will release histamine, leukotriene, prostaglandins and kinins when the immune system responded toward the antigen. This acute onset hypersensitivity occurs within 30 minutes, causing sign and symptoms ranging from rhinitis, urticarial, angioedema, pruritus, asthma and anaphylaxis which can cause death.

A study has been done for UK Adverse Reaction Reporting Project [15], where in 23 months period they received 369 reports on adverse reactions to protective gloves used in dental practices. Dentists were the largest group reported with gloves hypersensitivity where $47 \%$ reported with the adverse reactions, followed by dental nurses $(25 \%)$, patients $(22 \%)$, hygienists $(4 \%)$ and technicians $(2 \%)$. It is also show that the most occurring hypersensitivity 
is the type I and type IV hypersensitivity. In contrast to that, a study done among Malaysian dental personnel in Kelantan found that the highest prevalence of allergy reaction was irritant dermatitis $(18.5 \%)$, type IV hypersensitivity $(6.7 \%)$ followed by $1.7 \%$ type I hypersensitivity.

Dental personnel are highly associated with latex sensitivity and they are at high risk for the sensitization. This is due to the longer duration of exposure to latex glove which associated with latex glove allergy. [16] Wrangsjo [17] in his study finds out that $40 \%$ of the dentists questioned wore gloves for more than six hours per day, in which he concludes that dentist wears gloves for longer periods of times, as compared with other dental staff. It is synchronized with reports from Jolanski et al., [5]where dentist is reported with higher adverse reactions relating to glove use than the other subject groups of physicians and nurses. Tarlo et al., 1997 [16] found out that there is increasing number (a 10-fold increase) of dental students became sensitized to latex protein between their first and fourth year of training. A.Yusoff [3] also supported that the longer duration of exposure to latex glove significantly associated with the glove allergy.

\section{Rationale}

In AIMST dental polyclinic, gloves supplied for clinical daily basis need are from natural latex origin. However, the prevalence of hypersensitivity to latex gloves in AIMST Polyclinic is unknown. This study is conducted to identify the dental personnel having latex glove hypersensitivity, as the symptoms will affect the productivity of their work in clinic. This study aims to determine the prevalence of hypersensitivity symptoms among dental personnel in AIMST, and subsequently identify the most common symptoms reported by the dental personnel. Besides, we would like to investigate a significant relationship between duration of latex glove exposure and latex glove hypersensitivity. The outcome of this study will be the reference for AIMST dental centre in reducing the risk of latex hypersensitivity among the dental personnel. This study also discusses about the recommendations for managing latex glove adverse reactions in the clinical dental settings.

The aim of this study is to determine the prevalence of selfreported latex glove hypersensitivity among dental personnel of AIMST University, Faculty of Dentistry.

The objectives of the project are:

1. To determine association between latex gloves allergy and various factors like gender, age, years and duration of latex gloves exposure and other allergic parameters.

2. To determine the latex allergy related symptoms.

3. To identify the various precautions taken to minimize the symptoms of latex glove allergy.

\section{Materials and Methods}

\section{Study area}

The present study was carried out for a period of 2 months, from April 2019 to May 2019, in AIMST Dental Institute, Kedah to determine the prevalence of allergy to latex gloves among dental practitioners. Respondents was briefed and well understood re- garding the voluntariness and confidentiality of their data prior to participation in this study and informed consent was obtained.

\section{Study population and sampling procedure}

A cross-sectional survey was conducted using a standardised questionnaire. 234 respondents were selected comprising of dental specialist, dentist, dental students, dental surgery assistant, dental clinic assistants, dental laboratory technician and dental radiographer.

Questionnaire adapted from Yusoff A. et al (2013), self-administrative questionnaire to assess latex glove allergy was used as the instrument for data collection.

\section{Inclusion criteria}

1. Dental health-care personnel in AIMST Dental Institute, Kedah.

2. Subjects who provide consent to participate in the study.

\section{Exclusion criteria}

1. Subjects who were not available at the time of the study.

2. Subject who did not provide consent to participate in the study. 3. Incomplete survey forms.

\section{Questionnaire}

To investigate latex glove hypersensitivity among dental personnel in AIMST University, a questionnaire adopted from Yusoff A. et al (2013), self-administrative questionnaire to assess latex glove allergy was used in the study. It consists of 16 items which are divided into demographic details and respondents' information on latex gloves hypersensitivity symptoms.

The demographic questions are related to the age, gender, race, job title, number of patients attended per day, types of gloves used and duration of using latex gloves in dental field. The duration of using latex glove was explicitly asked on the hours per days and years of glove usage. Respondents were required to answer question regarding their working habits such as washing hand before using gloves, changing gloves between each patient and washing hands after treating each patients. History of atopic illness was asked through questions of history of asthma, allergic rhinitis, atopic dermatitis, hives or angioedema. History of allergy to fruits was also asked whether respondents has allergy to avocado, banana, chestnut, kiwi, ground nuts, papaya, peach and tomato.

The symptoms of latex hypersensitivity was categorised based on the types of reactions to latex products. Respondents were required to answer the polar questions in this section based on their experience when exposed to latex glove. Categorised symptoms are dry, cracked, irritated skin (irritant contact dermatitis); papular, pruritic rash, vesicles, and blisters after 48 hours of contact (delayed hypersensitivity or allergic contact dermatitis-Type IV reaction); and development of localised or generalised urticarial, vomiting, faintness, rhinitis, conjunctivitis, bronchospasm and anaphylactic shock immediately or within minutes of contact (immediate hypersensitivity type I). Physician diagnosed latex allergy was also asked for type I hypersensitivity 
reactions. Respondents' history of allergy to other latex product and any precautions taken to minimise symptoms related to latex glove use were also asked.

\section{Statistical Analysis}

The Statistical Package for the Social Sciences (SPSS version 27) and Microsoft Office Excel 2015 were used for data processing and analysis. Variables were described using frequency and percentage distribution. Chi-square test was used to assess the association between the variables and latex glove allergy. The level of significance was set as $\mathrm{P} \leq 0.05$.

\section{Results}

A total of 234 dental personnel in AIMST University, Dental Faculty, were surveyed. 73 were males whereas 161 were females. 3 were less than 20 years old, 186 were age ranged between 20 to 30 years old, 27 were age ranged between 30 to 40 years old and there were 18 participants who were more than 40 years old.

The prevalence of allergy to latex gloves by demographic variables is summarized in Table 2. A total of 58 (24.8\%) dental personnel reported allergy to latex gloves $(\mathrm{P}=0.028)$. Based on the gender, females $(73.3 \%)$ reported greater allergy to latex gloves than males $(20.5 \%)$. With regard to age, $22.2 \%$ of dental personnel aged below 30 years old and $35.6 \%$ of dental personnel aged above 30 years old reported significantly allergy to latex gloves $(\mathrm{P}$ $=0.024)$.

Based on ethnicity, $30 \%$ of Malay, $18.8 \%$ of Chinese, $45.5 \%$ of Indians and $20 \%$ of other ethnicity reported allergy to latex gloves $(\mathrm{P}=0.003)$. With regard to job title, $48 \%$ of dental surgeons, $21.5 \%$ of dental students, $25 \%$ of dental nurses, $35.7 \%$ of dental surgery assistants and none of dental technologists reported allergy to latex gloves $(\mathrm{P}=0.028)$.

With regard to years of gloves used, it was found that $(38.3 \%)$ respondents who wore gloves more than 5 years reported significantly allergy to latex gloves $(\mathrm{P}=0.016)$ than $(21.4 \%)$ respondents who wore gloves less than 5 years.

With regard to duration of glove usage, respondents (50\%) who wore gloves more than 5 hours per day had significantly greater allergy to latex gloves than those who wore gloves for less than 5 hours per day $(21.4 \%)(\mathrm{P}=0.002)$. With regard to number of patient attended per day, it was found out that respondents $(57.1 \%)$ who treated more than 10 patients per day had significantly greater allergy than respondents who treated 6 to $10 \mathrm{pa}-$ tients per day $(41.2 \%)$ and less than 5 patients per day $(21.2 \%)$ $(\mathrm{P}=0.003)$, which relates also to the increased duration of glove usage (Table 1).

Table 3 summarizes the prevalence of allergy to latex gloves in association with other allergy parameters. Among dental personnel who were allergic to latex gloves, $63.6 \%$ had a history of contact dermatitis, eczema and $56.8 \%$ had history of asthma $(\mathrm{P}=0.000)$. This indicated that patient who were asthmatic has higher risk of developing latex allergy. Increased prevalence of allergy to latex gloves was significantly associated with history of food or drug allergy $(\mathrm{P}=0.014)$ and history of allergy to pollen grains $(\mathrm{P}=$ 0.013) (Table 2).

With regard to precautions taken by the affected individuals to

Table 2. The prevalence of allergy to latex gloves by demographic variables.

\begin{tabular}{|c|c|c|c|c|}
\hline Variables & Total & Allergic to latex gloves $n(\%)$ & Non-allergic to latex gloves $\mathrm{n}(\%)$ & $P$ value \\
\hline $\begin{array}{l}\text { Gender } \\
\\
\text { Male } \\
\text { Female }\end{array}$ & $\begin{array}{c}73 \\
161\end{array}$ & $\begin{array}{l}15(20.5 \%) \\
43(73.3 \%)\end{array}$ & $\begin{array}{c}58(79.5 \%) \\
118(26.7 \%)\end{array}$ & 0.199 \\
\hline $\begin{array}{l}<30 \text { years } \\
>30 \text { Years }\end{array}$ & $\begin{array}{c}189 \\
45\end{array}$ & $\begin{array}{l}42(22.2 \%) \\
16(35.6 \%)\end{array}$ & $\begin{array}{c}147(77.8 \%) \\
29(64.4 \%)\end{array}$ & $0.024 *$ \\
\hline $\begin{array}{l}\text { Ethnicity } \\
\qquad \begin{array}{l}\text { Malay } \\
\text { Chinese } \\
\text { Indian } \\
\text { Others }\end{array}\end{array}$ & $\begin{array}{c}20 \\
165 \\
44 \\
5\end{array}$ & $\begin{array}{c}6(30 \%) \\
31(18.8 \%) \\
20(45.5 \%) \\
1(20 \%)\end{array}$ & $\begin{array}{c}14(70 \%) \\
134(81.2 \%) \\
24(54.5 \%) \\
4(80 \%)\end{array}$ & $0.003^{*}$ \\
\hline $\begin{array}{l}\text { Job title } \\
\text { Dental Surgeons } \\
\text { Dental Students } \\
\text { Dental Nurses } \\
\text { Dental Surgery Assistants } \\
\text { Dental Technologists }\end{array}$ & $\begin{array}{c}25 \\
186 \\
4 \\
14 \\
5\end{array}$ & $\begin{array}{c}12(48 \%) \\
40(21.5 \%) \\
1(25 \%) \\
5(35.7 \%) \\
0(0 \%)\end{array}$ & $\begin{array}{c}13(52 \%) \\
146(78.5 \%) \\
3(75 \%) \\
9(64.3 \%) \\
5(100 \%)\end{array}$ & $0.028^{*}$ \\
\hline $\begin{array}{r}\text { Years of glove usage } \\
<5 \text { Years } \\
>5 \text { Years }\end{array}$ & $\begin{array}{c}187 \\
47\end{array}$ & $\begin{array}{l}40(21.4 \%) \\
18(38.3 \%)\end{array}$ & $\begin{array}{c}147(78.6 \%) \\
29(61.7 \%)\end{array}$ & $0.016^{*}$ \\
\hline $\begin{array}{r}\text { Duration of glove usage } \\
\quad<5 \text { hours per day } \\
>5 \text { hours per day }\end{array}$ & $\begin{array}{c}208 \\
26\end{array}$ & $\begin{array}{c}45(21.6 \%) \\
13(50 \%)\end{array}$ & $\begin{array}{c}163(78.4 \%) \\
13(50 \%)\end{array}$ & $0.002^{*}$ \\
\hline $\begin{array}{l}\text { Number of patient attended per } \\
\text { day } \\
\qquad \begin{array}{l}0-5 \text { patients } \\
6-10 \text { patients } \\
>10 \text { patients }\end{array}\end{array}$ & $\begin{array}{c}203 \\
17 \\
14\end{array}$ & $\begin{array}{l}43(21.2 \%) \\
7(41.2 \%) \\
8(57.1 \%)\end{array}$ & $\begin{array}{c}160(78.8 \%) \\
10(58.8 \%) \\
6(42.9 \%)\end{array}$ & $0.003^{*}$ \\
\hline
\end{tabular}


Figure 1. Bar Diagram depicting the prevalence of latex allergy with age.

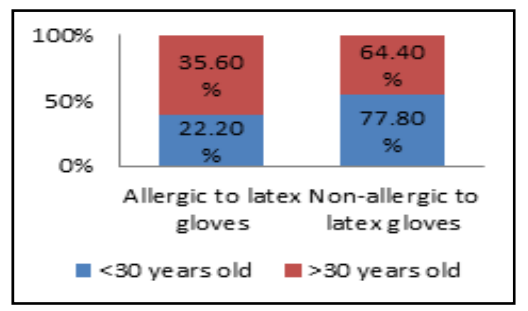

Figure 2. Bar Diagram depicting the prevalence of latex allergy with years of glove usage.

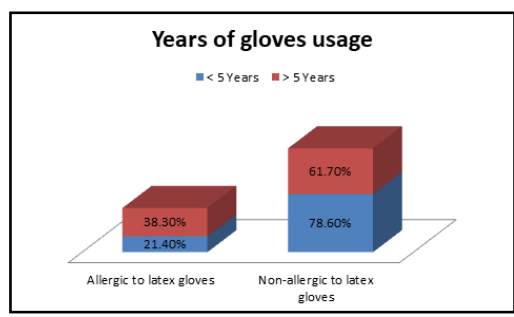

Figure 3. Bar Diagram depicting the prevalence of latex allergy with duration of glove usage.

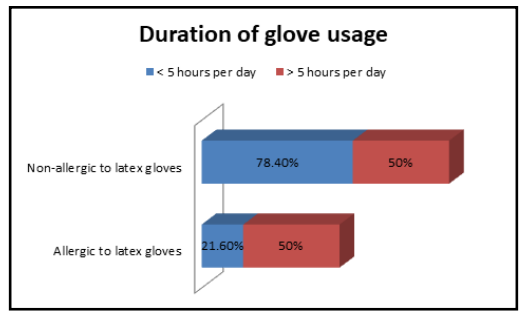

Figure 4. Bar Diagram depicting the prevalence of latex allergy with number of patients attended per day.

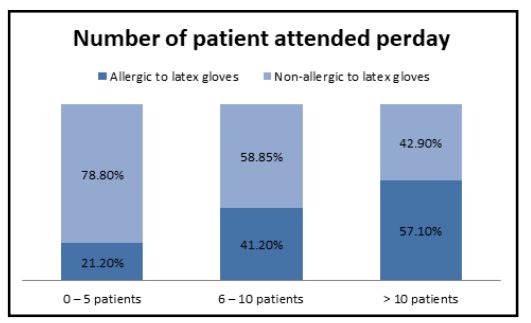

Table 3. The prevalence of allergy to latex gloves by various allergy parameters.

\begin{tabular}{|c|c|c|c|}
\hline Various allergies & Total & Allergy to latex gloves (\%) & $P$ value \\
\hline $\begin{array}{l}\text { History of food or drug allergy } \\
\text { Yes } \\
\text { No }\end{array}$ & $\begin{array}{c}30 \\
204\end{array}$ & $\begin{array}{l}13(43.3 \%) \\
45(22.1 \%)\end{array}$ & $0.014 *$ \\
\hline $\begin{array}{l}\text { History of contact dermatitis, eczema } \\
\text { Yes } \\
\text { No }\end{array}$ & $\begin{array}{c}22 \\
212\end{array}$ & $\begin{array}{l}14(63.6 \%) \\
44(20.8 \%)\end{array}$ & $0.000^{*}$ \\
\hline $\begin{array}{c}\text { History of asthma } \\
\text { Yes } \\
\text { No } \\
\end{array}$ & $\begin{array}{c}37 \\
197\end{array}$ & $\begin{array}{l}21(56.8 \%) \\
37(18.8 \%)\end{array}$ & $0.000^{*}$ \\
\hline $\begin{array}{l}\text { History of allergy to pollen grains } \\
\text { Yes } \\
\text { No }\end{array}$ & $\begin{array}{c}15 \\
219\end{array}$ & $\begin{array}{c}8(53.3 \%) \\
50(22.8 \%)\end{array}$ & $0.013^{*}$ \\
\hline $\begin{array}{l}\text { History of rubber dam, amalgam or eugenol } \\
\text { Yes } \\
\text { No }\end{array}$ & $\begin{array}{c}4 \\
230\end{array}$ & $\begin{array}{c}1(25 \%) \\
57(24.8 \%)\end{array}$ & 0.683 \\
\hline $\begin{array}{c}\text { Family history of allergy } \\
\text { Yes } \\
\text { No }\end{array}$ & $\begin{array}{c}24 \\
210\end{array}$ & $\begin{array}{c}9(37.5 \%) \\
49(23.3 \%)\end{array}$ & 0.104 \\
\hline
\end{tabular}

* Significant at $\mathbf{P} \leq 0.05$ using chi-square test. 
minimize symptoms, it was found that $34.1 \%$ used powder-free gloves, $21.2 \%$ increase washing of hands, $16.5 \%$ did not take any precautions, $11.8 \%$ used nylon gloves, $9.4 \%$ used topical cream and $7.1 \%$ worked without gloves.

Among latex gloves related symptoms, the most common symptoms were rash (48.4\%) and pruritus (15.3\%).

\section{Discussion}

Dental personnel are at risk of latex allergy due to the regular use of latex gloves. The present cross-sectional study evaluated the prevalence of allergy to latex gloves, glove-related symptoms and factors contributing to this type of allergy among dental person-

Figure 5. Bar Diagram depicting the prevalence of latex allergy with food or drug allergy.

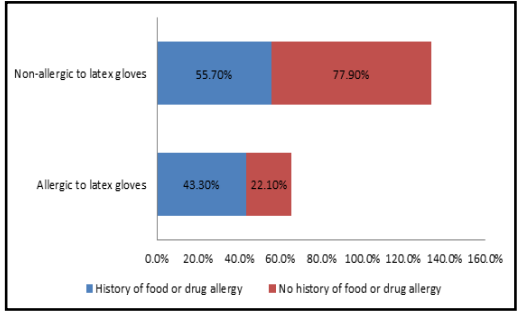

Figure 6. Bar Diagram depicting the prevalence of latex allergy with contact dermatitis

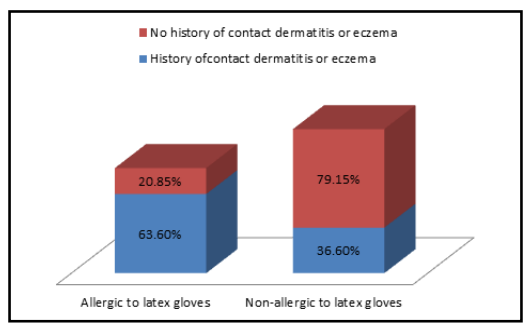

Figure 7. Bar Diagram depicting the prevalence of latex allergy with asthma.

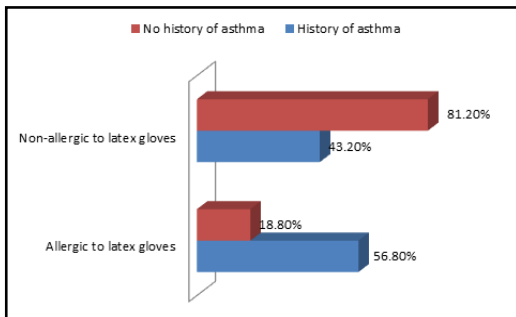

Figure 8. Bar Diagram depicting the prevalence of latex allergy with allergy to pollen grain
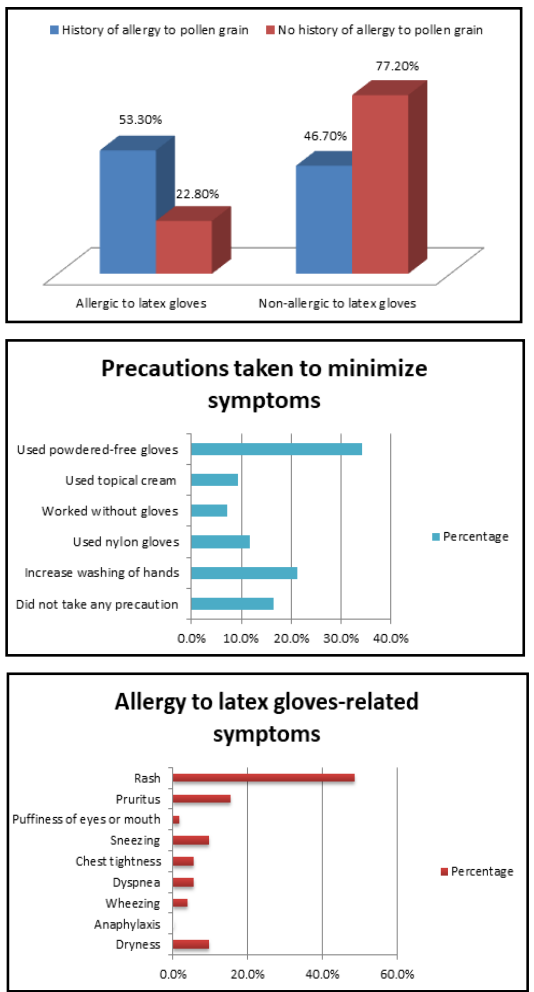
nel in AIMST University, Kedah. In this study, 24.8\% of respondents were reported to have latex glove allergy. It is slightly lower than recent study done among dental personnel in Kelantan with $27.6 \%$ reported by Azizah et.al 2013.

It is still within the range of most of other questionnaire-based studies published from 1992 to 2013 with prevalence of $13 \%$ to 33\%. (Berky 1992, Rankin 1993, Wrangsjo 1994, Katelaris, 1997, Gholizadeh 2010, Azizah 2013). Females had significantly greater allergy to latex gloves than males. $(\mathrm{P}=0.199)$ (Table 2) Similar result was found in the study by Azizah et.al 2013. Dental personnel with age above 30 had greater allergy to latex glove than those below 30. $(\mathrm{P}=0.024)$ (Table 2). Based on ethnicity, Indian had greatest allergy to latex glove followed by Malay and Chinese. $(\mathrm{P}=0.003)$ (Table 2).

One of the possible risk factors of latex glove allergy is duration and frequency of exposure. However, Nasuruddin et al., found that there were no association between duration of exposure and the presence of sensitization to latex among high risk groups in a Malaysian population. In contradiction, in our study it was found that there was an increase in the prevalence of allergy to latex gloves with increase in years of glove use $(\mathrm{P}=0.016)$ (Table 2). This is in agreement to few earlier studies (Azizah et.al 2013, Fatma Ayuni Mohd Rasdi et al. 2015). Also, the greater duration of gloves usage, more than 5 hours had a greater prevalence of latex glove allergy than those who used latex gloves less than 5 hours per day. $(\mathrm{P}=0.002)$ (Table 2).

Latex glove-related symptoms were significantly related to positive personal history of atopy. In the present study, the onset of allergic reaction to latex gloves was greatest directly following exposure. However, allergic reaction to latex gloves following exposure should fully or partly be regarded as irritant reaction. Individuals with immediate allergic reactions after exposure would not have the time to develop sensitization. Mikkola et al, (1998) demonstrated that the higher incidence of sensitization was noticed in the first 12 months of exposure. Gautrin et al, (2001) demonstrated that the incidence of occupation-related sensitization was greatest in the first 2 years of exposure and declined to incidence levels similar to those for common allergens after 4 years.

The majority of symptoms were mild with very few cases of generalized symptoms such as contact dermatitis, dryness, chest tightness, sneezing, pruritis, rash, eczema and asthma. There was a strong association between allergy to pollen grains and allergy to latex gloves $(\mathrm{P}=0.013)$ (Table 3). This type of allergy is significantly related to a positive history of common allergic symptoms and to a positive personal history of atopy, which is in agreement with the finding of other studies (Hollander et al, 1997; Blanco et al, 1999; Garabrant et al, 2001). This may be a significant finding as it would be advisable to perform precautionary allergy testing on those with a personal history of allergy. Moreover, there is also a strong association between allergy to food or drug and allergy to latex gloves. $(\mathrm{P}=0.014)$ (Table 3).

From the results, most of the dental personnel used powderedfree gloves $(34.1 \%)$ as a precaution to minimise symptoms related to latex glove allergy. While $21.2 \%$ of participants who has latex allergy, increased washing of hands as precautious measure to allergic reaction. Unfortunately, $16.5 \%$ of the participants who are allergic to latex gloves did not take any precautions.
As for prevention, the current dental practitioner and personnel should follow the guidelines provided by US National Institute of Occupational Safety and Health recommendations to reduce or prevent the incident of latex hypersensitivity in the clinic.

1. A use non latex glove is advisable for activities that are not likely to involve contact with infectious materials.

2. Appropriate barrier protection is needed when dealing with infectious materials. If latex glove is used, powder free gloves with reduced protein content is preferable.

3. Oil based hand creams or lotions is not advisable as it can cause glove deterioration. (Except for those who have shown to have reduced the symptoms)

4. Work areas need to be frequently cleaned and free from latex dust.

5. The ventilation filters and vacuum bags used in latex contaminated areas need to be changed frequently.

6. All personnel must recognise the symptoms of latex allergy; skin rashes, hives, flushing, itchiness, nasal, eye, or sinus symptoms, asthma and shock.

7. If there is symptoms of latex allergy, direct contact with the latex glove need to be avoided. An immediate action need to be taken to seek for the physician in treating the allergy.

Although a higher rate of allergic reactions to latex gloves was reported among dental personnel, relying on questionnaire data alone to determine the prevalence of allergy to latex gloves has obvious shortcomings. Confirmation of this prevalence rate requires an objective measure of $\mathrm{IgE}$ mediated hypersensitivity, such as skin testing with appropriate extracts, an in-vitro assay of specific $\mathrm{IgE}$ antibodies to the latex allergens, gloves provocation tests or skin patch testing to diagnose and identified the dental personnel with latex hypersensitivity.

\section{Conclusion}

In conclusion, approximately $24.8 \%$ of dental personnel in AIMST University have latex glove hypersensitivity.

1. Significant associations were found between latex glove allergy by various allergy parameters such as years of latex glove usage and duration of latex gloves usage, which implies that one of the possible risk factors of latex glove allergy is duration and frequency of exposure.

2. Further study and further medical assessment are recommended followed by specific measures to manage the hypersensitivity symptoms.

\section{References}

[1]. Chin SM, Ferguson JW, Bajurnows T. Latex allergy in dentistry. Review and report of case presenting as a serious reaction to latex dental dam. Aust Dent J. 2004 Sep;49(3):146-8. Pubmed PMID: 15497359.

[2]. Ong EL. Natural Rubber Latex Medical Gloves: Why They Are Still the Best. Article presented in seminar on "Selecting the right gloves: glove selection for healthcare and personal protective equipment"; 2005 March 11-14, Edinburgh.

[3]. A.Yusoff., SA.Murray, NA. Rahman, J John, D. Mohammad, MM Tin-Oo, Self-Reported Latex Glove Allergy among Dental Personnel in Kelantan State, Malaysia. International Medical Journal, 20(3): 323-325.

[4]. Tarlo SM, Sussman GL, Holness DL. Latex sensitivity in dental students and staff: a cross-sectional study. J Allergy Clin Immunol. 1997 Mar;99(3):396401. Pubmed PMID: 9058696. 
[5]. Sussman G, Gold M. Guidelines for the management of latex allergies and safe latex use in healthcare facilities. CHA Press; 1996 Mar.

[6]. Binkley HM, Schroyer T, Catalfano J. Latex allergies: a review of recognition, evaluation, management, prevention, education, and alternative product use. J Athl Train. 2003 Apr;38(2):133-40. Pubmed PMID: 16558678.

[7]. Connie Katelaris. Latex Reactions: Allergic and Non-Allergic Hypersensitivity.

[8]. Kean T, McNally M. Latex hypersensitivity: a closer look at considerations for dentistry. J Can Dent Assoc. 2009 May;75(4):279-82. Pubmed PMID: 19422750.

[9]. Krapp KM. Latex. Nicole Beatty (ed). How Products Are Made, 3rd ed. US: Gale; 1997

[10]. Latex Glove Production.

[11]. Yeang HY. Natural rubber latex allergens: new developments. Curr Opin Allergy Clin Immunol. 2004 Apr;4(2):99-104. Pubmed PMID: 15021061.

[12]. Sussman G, Gold M. Guidelines for the Management of Latex Allergies.

[13]. Guidelines for the Management of Latex Allergies.

[14]. Scott A, Gawkrodger DJ, Yeoman C, Egner W, van Noort R, Hatton PV, Grummitt J. Adverse reactions to protective gloves used in the dental profession: experience of the UK Adverse Reaction Reporting Project. Br Dent J. 2003 Dec 20;195(12):686-90. Pubmed PMID: 14718955.

[15]. Tarlo SM, Sussman GL, Holness DL. Latex sensitivity in dental students and staff: a cross-sectional study. J Allergy Clin Immunol. $1997 \mathrm{Mar} ; 99(3): 396-$ 401. doi: 10.1016/s0091-6749(97)70058-7. Pubmed PMID: 9058696.

[16]. Wrangsjö K, Wallenhammar LM, Ortengren U, Barregård L, Andreasson H,
Björkner B, Karlsson S, Meding B. Protective gloves in Swedish dentistry: use and side-effects. Br J Dermatol. 2001 Jul;145(1):32-7. Pubmed PMID: 11453904.

[17]. Jolanki R, Estlander T, Alanko K, Savela A, Kanerva L. Incidence rates of occupational contact urticaria caused by natural rubber latex. Contact Dermatitis. 1999 Jun;40(6):329-31. Pubmed PMID: 10385340

[18]. Chaiear N, Jindawong B, Boonsawas W, Kanchanarach T, Sakunkoo P. Glove allergy and sensitization to natural rubber latex among nursing staff at Srinagarind Hospital, Khon Kaen, Thailand. J Med Assoc Thai. 2006 Mar;89(3):368-76. Pubmed PMID: 16696422.

[19]. Huda H, Sundaru H, Harsal A, Karyadi TH, Prasetyo SB. Latex allergen sensitization due to glove use among hospital staff in Jakarta and related factors. Acta Med Indones. 2005 Jan-Mar;37(1):3-11. Pubmed PMID: 15986550.

[20]. Tang MB, Leow YH, Ng V, Koh D, Goh CL. Latex sensitisation in healthcare workers in Singapore. Ann Acad Med Singap. 2005 Jun;34(5):376-82. Pubmed PMID: 16021228.

[21]. Khader Y, Abu-Zaghlan M, Abu-Al Rish I, Burgan S, Amarin Z. Self-reported allergy to latex gloves among health care workers in Jordan. Contact Dermatitis. 2005 Dec;53(6):339-43. Pubmed PMID: 16364123.

[22]. Yusoff A. et al (2013). Self administrative questionnaire to assess latex glove allergy.

[23]. Agrawal A, Bhatt N, Kk S, Singh K, Chaudhary H, Asawa K. Prevalence of allergy to latex gloves among dental professionals in Udaipur, Rajasthan, India. Oral Health Prev Dent. 2010;8(4):345-50. Pubmed PMID: 21180671. 